\title{
Treatment satisfaction in cystic fibrosis: early patient experience with tobramycin inhalation powder
}

\author{
Jonathan Greenberg' \\ Jacqueline B Palmer ${ }^{2}$ \\ Wing W Chan ${ }^{2}$ \\ Catherine E Correia' \\ Diane Whalley ${ }^{3}$ \\ Paul Shannon ${ }^{3}$ \\ Gregory S Sawicki' \\ 'Division of Respiratory Diseases, \\ Boston Children's Hospital, Boston, \\ MA, ${ }^{2}$ Novartis Pharmaceuticals \\ Corporation, East Hanover, NJ, USA; \\ ${ }^{3}$ RTI Health Solutions, Manchester, UK
}

Correspondence: Jonathan Greenberg Boston Children's Hospital, 300 Longwood Avenue, Boston, MA, USA Email jonathan.greenberg@childrens. harvard.edu

submit your manuscrip Dovepress if in 0 http://dx,doi,org/10.2147/PPA.S102234
This article was published in the following Dove Press journal:

Patient Preference and Adherence

26 October 2016

Number of times this article has been viewed

Background: This study assessed treatment satisfaction of cystic fibrosis (CF) patients in a routine clinical setting for tobramycin inhalation powder (TIP), the first dry powder-inhaled antibiotic for Pseudomonas aeruginosa infection.

Methods: CF patients aged 6 years or older treated with at least one cycle of TIP completed a web survey on experience with TIP, including the Treatment Satisfaction Questionnaire for Medication (TSQM). Regression analysis determined the factors associated with TSQM global satisfaction.

Results: Eighty patients (mean age \pm standard deviation: $24.4 \pm 9.4$ years; $57.5 \%$ female; mean forced expiratory volume in 1 second \pm standard deviation: $67.1 \% \pm 27.3 \%$ predicted) completed the survey. The majority expressed satisfaction with TIP's administration time (100\%), time to clean (97.1\%), portability (97.1\%), and ease of use (94.3\%). Effectiveness was significantly associated with TSQM global satisfaction (regression $R$-squared: 0.54 ).

Conclusion: Patient preferences for TIP were based on administration time and ease of use. Global satisfaction was related to greater patient-perceived effectiveness.

Keywords: cystic fibrosis, patient satisfaction, tobramycin, dry powder inhalers

\section{Introduction}

Progressive obstructive lung disease and recurrent respiratory infections account for the majority of morbidity and mortality associated with cystic fibrosis (CF). ${ }^{1}$ Pseudomonas aeruginosa is a prevalent pathogen often responsible for chronic respiratory infections, which can lead to high health resource utilization and significant morbidity in patients with CF. Multidrug-resistant and extensively drug-resistant $P$. aeruginosa strains increase the therapeutic challenge of treating CF worldwide., ${ }^{2,3}$

Tobramycin-inhaled solution is a guideline-recommended therapy in both the US and Europe to manage chronic $P$. aeruginosa infections in patients with $\mathrm{CF}^{4-6}$ Studies have shown tobramycin inhalation solution to have significant benefits in relation to health-related quality of life (HRQOL), ${ }^{7}$ lung function, ${ }^{8}$ hospitalizations, ${ }^{9}$ and mortality. ${ }^{10}$ Treatment guidelines published in recent years have recognized the emerging availability of tobramycin inhalation powder (TIP) as an alternative to the inhaled solution. ${ }^{5,6}$ TIP is the first dry powder-inhaled antibiotic available for use in CF. It was approved by the Food and Drug Administration in the US in 2013, having been granted a marketing authorization in Europe in 2010 from the European Medicines Agency. In clinical studies, TIP generally has been well tolerated; it has also been shown to improve lung function relative to placebo ${ }^{11}$ and to be noninferior to tobramycin inhalation solution in its effect on forced expiratory volume in 1 second 
$\left(\mathrm{FEV}_{1}\right)$ percent predicted. ${ }^{12}$ A recent observational study further reported improved adherence, tolerability, and decreased exacerbation rates in a sample of 78 adult $\mathrm{CF}$ patients treated with TIP over 12 months, compared to patients' reports of the preceding 12 months using nebulized tobramycin. ${ }^{13}$

Nebulized tobramycin solution and TIP are both orally inhaled twice daily in alternating cycles of 28 days ontreatment followed by 28 days off-treatment. However, TIP has been shown to take considerably less time to administer than tobramycin-inhaled solution. ${ }^{14}$ From a patient perspective, shorter administration time, together with greater portability and ease of use, has the potential to convey benefits in relation to treatment burden. ${ }^{15}$

The objective of the current study was to assess the real-world experience of CF patients with TIP, focusing on patient-reported HRQOL, treatment satisfaction, and treatment experience.

\section{Patients and methods Study design and setting}

In this single-center, noninterventional, cross-sectional study, a web-based survey was administered to patients with $\mathrm{CF}$ (or their parents or caregivers). Participants were sampled consecutively at their regular CF care center visit at Boston Children's Hospital. If patients met the study inclusion criteria, the investigator obtained informed consent electronically from all of the participants 18 years of age and over to participate in the study. Informed assent was obtained for all of the participants less than 18 years of age and a parent or caregiver provided informed consent electronically. The study protocol was approved and reviewed by the institutional review board of Boston Children's Hospital.

The inclusion criteria for the study were: age $\geq 6$ years with a diagnosis of $\mathrm{CF}$, a history of $P$. aeruginosa lung infection, and the use of TIP during the 7 months prior to the survey. Patients aged 14 years or older self-completed the survey, whereas a parent or caregiver provided survey responses for younger patients. Eligible participants (or their parent or caregiver) completed the survey at the clinic on a tablet computer. Study data were collected and managed using Research Electronic Data Capture (REDCap) electronic data capture tools hosted at Boston Children's Hospital. ${ }^{16}$

\section{Study measures}

\section{Sociodemographic and clinical variables}

Patients (or their parent or caregiver) were asked questions regarding age, sex, ethnicity, relationship status, employment status, and education level. Each patient's FEV 1 and body mass index (BMI) were recorded from a medical record review at the time of the survey.

\section{Treatment experience}

Study-specific questions regarding experiences with TIP and nebulized antibiotic therapies were asked of patients who were currently using TIP and who had taken at least two cycles of a nebulized antibiotic in the previous year. Questions included reasons for choosing TIP and stopping the previous nebulized antibiotic, ease of switching to TIP, overall satisfaction and preferences between TIP and a nebulized antibiotic, and preferences for specific device attributes, such as administration time, ease of use, portability, effectiveness, cleaning time, and side effects. In addition, patients who had stopped taking TIP were asked their reasons for stopping.

\section{Treatment satisfaction}

The 14-item Treatment Satisfaction Questionnaire for Medication (TSQM, Version 1.4) ${ }^{17,18}$ was administered to patients currently using TIP. The TSQM is a generic, multidimensional, self-administered measure of patient satisfaction with a medication. The instrument has 14 items measuring four domains: effectiveness, side effects, convenience, and global satisfaction. Domain scores range from 0 to 100 , with a higher score indicating higher satisfaction. Respondents were instructed that the term "medication" in the TSQM referred to TIP and should be considered as the combination of the medication and the delivery device.

\section{HRQOL}

The Cystic Fibrosis Questionnaire-Revised (CFQ-R) ${ }^{19}$ was administered to all patients in the study, regardless of whether or not they were currently using TIP. The CFQ-R is a disease-specific instrument used to measure the impact of $\mathrm{CF}$ on overall health, daily life, perceived well-being, and symptoms. Two versions were used in this study: one for adult and adolescent patients (aged $\geq 14$ years), and one for parents or caregivers of pediatric patients (aged 6-13 years). The adult/adolescent version has 12 domains: physical functioning, role, vitality, emotional functioning, social functioning, body image, eating disturbances, treatment burden, health perceptions, weight, respiratory symptoms, and digestive symptoms. The parent/caregiver version has eleven domains: physical functioning, school functioning, vitality, emotional functioning, body image, eating disturbances, treatment burden, health perceptions, weight, respiratory symptoms, and digestive symptoms. 


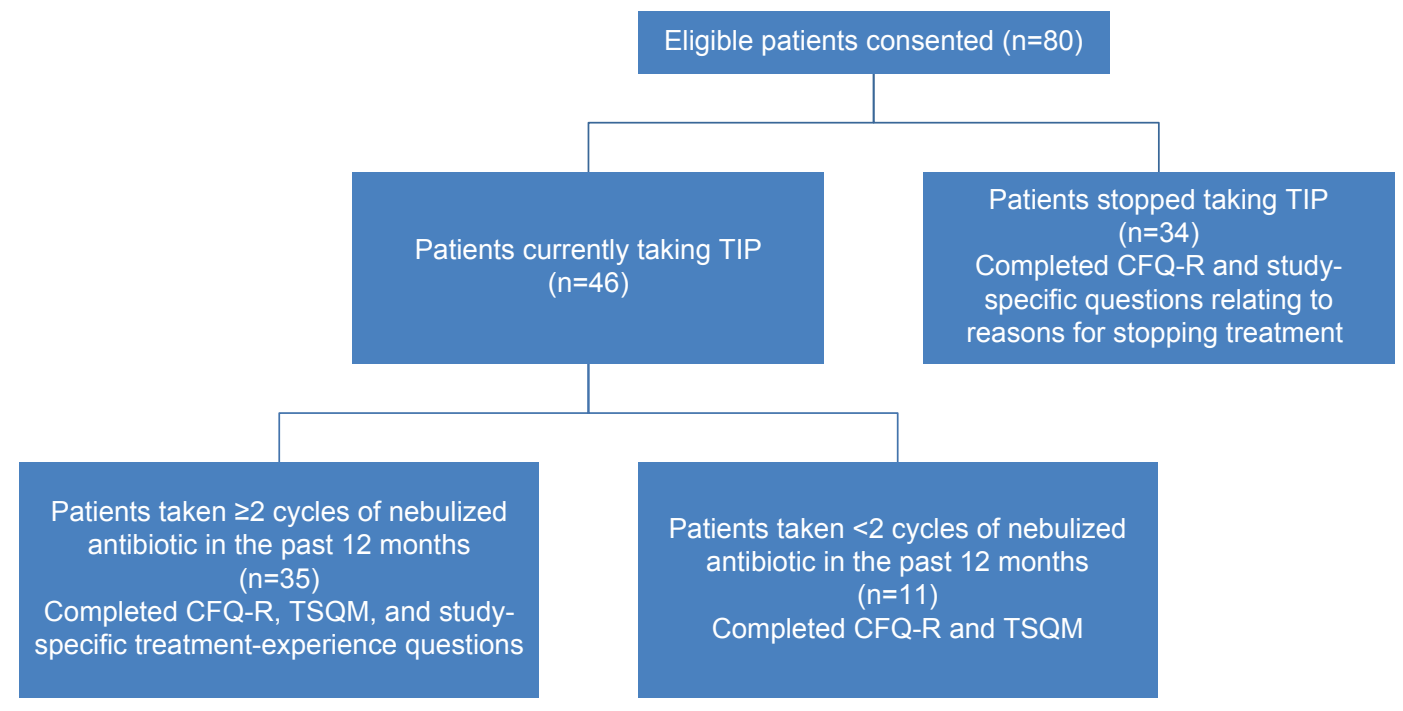

Figure I Flowchart of patient participation.

Abbreviations: CFQ-R, Cystic Fibrosis Questionnaire-Revised; TIP, tobramycin inhalation powder; TSQM, Treatment Satisfaction Questionnaire for Medication.

Domain scores on both versions range from 0 to 100 , with higher scores indicating better HRQOL.

Figure 1 illustrates the patterns of use of TIP and nebulized antibiotics among the samples recruited for the study, as well as the associated study measures that these patients completed. The figure shows that the CFQ-R was completed by all 80 patients, and the TSQM was completed by the 46 patients currently taking TIP. Study-specific treatmentexperience questions were completed by 35 patients who were currently taking TIP and had taken at least two cycles of a nebulized antibiotic in the past 12 months (26 of these patients were currently alternating another antibiotic therapy with TIP). Study-specific questions relating to reasons for stopping treatment were completed by 34 patients who had stopped taking TIP.

\section{Statistical analysis}

Study measures were summarized descriptively through mean values, standard deviations, medians, and interquartile ranges for TSQM and CFQ-R domain scores and by frequency distributions for the individual treatment-experience questions.

Ordinary least squares (OLS) regression was used to model TSQM global satisfaction domain scores. Independent variables in the model included the three remaining domain scores (effectiveness, side effects, and convenience) from the TSQM, number of cycles of TIP taken, and key domains of the CFQ-R (treatment burden, respiratory symptoms, and health perceptions). Additional patient characteristics also included in the model were age, sex, work, or school status, $\mathrm{FEV}_{1}$ percent predicted, BMI, and the education level of the respondent (or parent or caregiver of a pediatric patient aged 6-13 years). The fitted model was reduced using the stepwise elimination method. A $P$-value of 0.2 was selected as the criterion for removal of predictors (and 0.5 for reentry) to ensure that potential influential, albeit nonsignificant, variables were retained in the model.

\section{Results \\ Sociodemographic and clinical characteristics}

A total of 80 participants (patients, parents, or caregivers) met the study criteria and agreed to participate in the study. Of these, $64(80 \%)$ were adult patients aged 18-50 years, eight (10\%) were adolescent patients aged $14-17$ years, and eight (10\%) were parents (all mothers) of pediatric patients aged 10-13 years. Seven patients $(8.8 \%)$ had not completed one full cycle of TIP, 18 (22.5\%) had completed one cycle, $16(20.0 \%)$ had completed two cycles, 14 (17.5\%) had completed three cycles, and 25 (31.3\%) had completed four or more cycles. Table 1 presents the baseline demographic and clinical characteristics of the sample.

\section{Patient experience of TIP and nebulized antibiotics}

\section{Transitioning to TIP}

Over three-quarters of participants (77.1\%) chose to use TIP based on advice from their doctor. Other common reasons for choosing TIP included the expectation that it would be more convenient (34.3\%), quicker to use (34.3\%), easier to use $(28.6 \%)$, and help the patient take his or her medication 
Table I Patient baseline sociodemographic and clinical characteristics

\begin{tabular}{|c|c|c|c|}
\hline Characteristic & $\begin{array}{l}\text { All } \\
\text { patients } \\
(\mathbf{N}=\mathbf{8 0})\end{array}$ & $\begin{array}{l}\text { Currently } \\
\text { taking TIP } \\
(n=46)\end{array}$ & $\begin{array}{l}\text { Stopped } \\
\text { TIP } \\
(n=34)\end{array}$ \\
\hline \multicolumn{4}{|l|}{ Sex, n (\%) } \\
\hline Male & $34(42.5)$ & $23(50.0)$ & II (32.4) \\
\hline Female & $46(57.5)$ & $23(50.0)$ & $23(67.6)$ \\
\hline \multicolumn{4}{|l|}{ Age, years } \\
\hline Mean (SD) & $24.4(9.4)$ & $24.8(9.7)$ & $23.9(9.1)$ \\
\hline Range & $10-50$ & $10-50$ & $10-50$ \\
\hline \multicolumn{4}{|l|}{ Race/ethnicity, n (\%) } \\
\hline Caucasian & $76(95.0)$ & $45(97.8)$ & 31 (9I.2) \\
\hline Other & $4(5.0)$ & I (2.2) & $3(8.8)$ \\
\hline \multicolumn{4}{|l|}{ Marital status, ${ }^{a}$ n (\%) } \\
\hline Single/never married & $51(70.8)$ & $30(7 \mathrm{I} .4)$ & $21(70.0)$ \\
\hline Married/with partner & $20(27.8)$ & $12(28.6)$ & $8(26.7)$ \\
\hline Divorced & I (I.4) & $0(0.0)$ & $\mathrm{I}(3.3)$ \\
\hline \multicolumn{4}{|l|}{ Education, ${ }^{\mathrm{a}} \mathrm{n}(\%)$} \\
\hline Vocational school or less & $22(30.6)$ & $13(31.0)$ & $9(30.0)$ \\
\hline Some college or higher & $50(69.4)$ & $29(69.0)$ & $21(70.0)$ \\
\hline \multicolumn{4}{|l|}{ Employment status, ${ }^{\mathrm{a}} \mathrm{n}(\%)$} \\
\hline Working/full-time education & $53(73.6)$ & 31 (73.8) & $22(73.3)$ \\
\hline Not working & $19(26.4)$ & II (26.2) & $8(26.7)$ \\
\hline \multicolumn{4}{|l|}{ FEV,$\%$ predicted } \\
\hline Mean (SD) & $67.1(27.3)$ & $60.2(27.6)$ & $76.5(24.3)$ \\
\hline Median (QI, Q3) & $\begin{array}{l}71.0 \\
(43.0,90.0)\end{array}$ & $\begin{array}{l}62.0 \\
(34.0,81.0)\end{array}$ & $\begin{array}{l}83.5 \\
(57.0,95.0)\end{array}$ \\
\hline \multicolumn{4}{|l|}{ BMI } \\
\hline Mean (SD) & $21.1(3.0)$ & $20.9(3.4)$ & $21.3(2.5)$ \\
\hline Median (QI, Q3) & $\begin{array}{l}20.6 \\
(19.2,22.9)\end{array}$ & $\begin{array}{l}20.0 \\
(19.0,22.5)\end{array}$ & $\begin{array}{l}21.3 \\
(19.5,22.9)\end{array}$ \\
\hline
\end{tabular}

Note: administered only to adolescent and adult patients $(n=72)$.

Abbreviations: BMI, body mass index; $\mathrm{FEV}_{\mathrm{l}}$, forced expiratory volume in I second; $\mathrm{Q}$, quartile; SD, standard deviation; TIP, tobramycin inhalation powder.

more regularly (22.9\%). The majority of participants found switching to TIP to be very easy $(71.4 \%)$ or easy $(20.0 \%)$. Only two patients $(5.7 \%)$ reported that switching to TIP was difficult.

\section{Treatment preferences}

All patients $(n=35)$ who completed the study-specific treatment-experience questions expressed a preference for TIP over a nebulized antibiotic in relation to administration time (Table 2). Over $90 \%$ of these patients also preferred TIP for its ease of use, portability, and time to clean. Comparatively more patients expressed no preference between TIP and a nebulized antibiotic in relation to effectiveness and side effects, although approximately one-half of the patients still preferred TIP. Over half of the patients (57.1\%) also reported that they would be more likely to use TIP regularly as prescribed, compared with only $11.4 \%$ who would be more likely to use a nebulizer regularly and $31.4 \%$ who reported that they would use both TIP and a nebulizer regularly as prescribed.
Table 2 Preference between TIP and nebulized antibiotic $(n=35)$

\begin{tabular}{llll}
\hline Device attribute & $\begin{array}{l}\text { Prefer } \\
\text { TIP, n (\%) }\end{array}$ & $\begin{array}{l}\text { No } \\
\text { preference, } \\
\mathbf{n}(\%)\end{array}$ & $\begin{array}{l}\text { Prefer } \\
\text { nebulized } \\
\text { antibiotic, n (\%) }\end{array}$ \\
\hline Administration time & $35(100.0)$ & $0(0.0)$ & $0(0.0)$ \\
Time it takes to clean & $34(97.1)$ & $0(0.0)$ & $1(2.9)$ \\
Portability & $34(97.1)$ & I (2.9) & $0(0.0)$ \\
Ease of use & $33(94.3)$ & $0(0.0)$ & $2(5.7)$ \\
Effectiveness & I8 (5I.4) & I3 (37.I) & $4(11.4)$ \\
Side effects & $17(48.6)$ & I5 (42.9) & $3(8.6)$ \\
\hline
\end{tabular}

Abbreviation: TIP, tobramycin inhalation powder.

Patients were presented with a list of inhaler device attributes and asked to select the most important and the least important features of an inhaled antibiotic treatment and of TIP specifically (Table 3). The attribute most commonly reported as the most important was administration time: approximately one-half of the patients considered this the most important feature of an inhaled antibiotic treatment and of TIP. Approximately three-quarters of the patients considered cost the least important feature. Differences between an inhaled antibiotic and TIP were evident in relation to the features ease of use and effectiveness: a greater proportion of patients considered ease of use the most important feature of TIP when compared with an inhaled antibiotic treatment. The opposite was the case for effectiveness.

\section{Reasons for stopping treatment}

Thirty-four participants had stopped taking TIP. The most common reason $(41.2 \%)$ given for stopping was that it treated the patient's infection or the patient completed treatment. Other reasons given included side effects $(17.6 \%)$, clinician recommendation (14.7\%), end of cycle (11.8\%), and lack of insurance coverage (5.9\%). There was no significance $(P=0.169)$ in sex among those who stopped taking TIP. For the 35 patients who completed the study-specific

Table 3 Patient priorities for features of inhaled antibiotic treatments

\begin{tabular}{|c|c|c|c|c|}
\hline \multirow[t]{2}{*}{$\begin{array}{l}\text { Device } \\
\text { attribute }\end{array}$} & \multicolumn{2}{|c|}{$\begin{array}{l}\text { Inhaled antibiotic } \\
\text { treatment }\end{array}$} & \multicolumn{2}{|l|}{ TIP } \\
\hline & $\begin{array}{l}\text { Most } \\
\text { important, } \\
\text { n (\%) }\end{array}$ & $\begin{array}{l}\text { Least } \\
\text { important, } \\
\text { n (\%) }\end{array}$ & $\begin{array}{l}\text { Most } \\
\text { important, } \\
\text { n (\%) }\end{array}$ & $\begin{array}{l}\text { Least } \\
\text { important, } \\
\text { n (\%) }\end{array}$ \\
\hline $\begin{array}{l}\text { Administration } \\
\text { time }\end{array}$ & 17 (48.6) & $0(0.0)$ & $16(45.7)$ & $2(5.7)$ \\
\hline Ease of use & $3(8.6)$ & I (2.9) & $9(25.7)$ & I (2.9) \\
\hline Portability & I (2.9) & $6(17.1)$ & $5(14.3)$ & $5(14.3)$ \\
\hline Effectiveness & II (3I.4) & $0(0.0)$ & $3(8.6)$ & $0(0.0)$ \\
\hline Cost & $0(0.0)$ & 25 (7I.4) & $0(0.0)$ & 25 (7I.4) \\
\hline Other & I (2.9) & I (2.9) & $0(0.0)$ & $0(0.0)$ \\
\hline
\end{tabular}

Abbreviation: TIP, tobramycin inhalation powder. 
Table 4 OLS regression on TSQM global satisfaction domain scores $(n=46)$

\begin{tabular}{|c|c|c|c|}
\hline Independent variable & Estimate (SE) & $95 \% \mathrm{Cl}$ & $P$-value \\
\hline \multicolumn{4}{|l|}{ Initial model $(R$-squared $=0.59)$} \\
\hline TSQM effectiveness score & $0.76(0.16)$ & $0.45,1.06$ & $<0.001$ \\
\hline TSQM side-effects score & $0.21(0.14)$ & $-0.06,0.48$ & 0.119 \\
\hline TSQM convenience score & $-0.08(0.14)$ & $-0.34,0.19$ & 0.561 \\
\hline $\begin{array}{l}\text { Patient sex }(0=\text { female, } \\
I=\text { male })\end{array}$ & $4.94(4.93)$ & $-4.73, \mid 4.61$ & 0.317 \\
\hline Patient age & $-1.35(1.01)$ & $-3.34,0.64$ & 0.183 \\
\hline Squared patient age & $0.02(0.02)$ & $-0.02,0.05$ & 0.284 \\
\hline Work/school status ${ }^{a}$ & $-1.87(4.91)$ & $-11.50,7.76$ & 0.704 \\
\hline Education level $^{\mathrm{b}}$ & $7.49(4.47)$ & $-1.27,16.25$ & 0.094 \\
\hline $\mathrm{FEV}_{1}$ & $-0.15(0.09)$ & $-0.33,0.03$ & 0.108 \\
\hline BMI & $0.46(0.79)$ & $-1.09,2.01$ & 0.561 \\
\hline CFQ-R respiratory score & $-0.06(0.18)$ & $-0.4 I, 0.30$ & 0.750 \\
\hline $\begin{array}{l}\text { CFQ-R health perception } \\
\text { score }\end{array}$ & $0.15(0.14)$ & $-0.12,0.42$ & 0.281 \\
\hline $\begin{array}{l}\text { CFQ-R treatment burden } \\
\text { score }\end{array}$ & $0.03(0.12)$ & $-0.20,0.26$ & 0.803 \\
\hline $\begin{array}{l}\text { Number of TIP cycles } \\
\text { completed }^{c}\end{array}$ & $-0.7 I(4.25)$ & $-9.05,7.62$ & 0.867 \\
\hline Intercept & I $3.57(24.98)$ & $-35.40,62.53$ & 0.587 \\
\hline \multicolumn{4}{|c|}{ Final model following stepwise elimination $(R$-squared $=0.54)$} \\
\hline TSQM effectiveness score & $0.75(0.12)$ & $0.52,0.98$ & $<0.001$ \\
\hline TSQM side effects score & $0.23(0.12)$ & $-0.02,0.47$ & 0.069 \\
\hline Education level ${ }^{b}$ & $5.77(4.03)$ & $-2.12,13.67$ & 0.152 \\
\hline Intercept & $-4.14(13.40)$ & $-30.41,22.13$ & 0.757 \\
\hline
\end{tabular}

Notes: ${ }^{2}$ Asked of parent or caregiver for children $6-13$ years old; $0=$ not currently working/at school, I= currently working/at school; ' ${ }^{\mathrm{A}}$ Asked of parent or caregiver for children $6-13$ years old; $0=$ less than college education, I= some college education or higher; ${ }^{c} 0=4$ or more cycles, $\mathrm{I}=3$ or fewer cycles.

Abbreviations: BMI, body mass index; CFQ-R, Cystic Fibrosis QuestionnaireRevised; $\mathrm{Cl}$, confidence interval; $\mathrm{FEV}_{\text {, }}$, forced expiratory volume in I second; OLS, ordinary least squares; SE, standard error; TSQM, Treatment Satisfaction Questionnaire for Medication; TIP, tobramycin inhalation powder.

treatment-experience questions, the most common reasons for stopping their last nebulized antibiotic were its long-term use $(45.7 \%)$ and clinician recommendation $(22.9 \%)$. Other reasons included side effects $(8.6 \%)$, lack of effectiveness $(8.6 \%)$, too difficult to use $(5.7 \%)$, and the patient asked for something new $(5.7 \%)$.

\section{HRQOL}

CFQ-R scores on many of the domains were similar for patients currently using TIP and for those who had stopped. The greatest difference in mean scores was evident on the physical functioning (using TIP $=64.3, \mathrm{n}=46$; stopped TIP $=73.1$, $\mathrm{n}=34$ ), treatment burden (using TIP $=48.1, \mathrm{n}=46$; stopped TIP $=58.8, \mathrm{n}=34$ ), and school functioning domains (using $\mathrm{TIP}=86.1, \mathrm{n}=4$; stopped TIP $=75.0, \mathrm{n}=4$ ).

\section{Treatment satisfaction}

Patients were asked whether they were more satisfied overall with TIP or with a nebulized antibiotic; $71.4 \%$ were more satisfied with TIP, $17.1 \%$ were more satisfied with a nebulized antibiotic, and the remaining $11.4 \%$ reported no preference. More patients preferred to continue on TIP (77.1\%) than preferred to switch to a nebulized antibiotic (11.4\%).

TSQM domain scores supported the high levels of treatment satisfaction among patients currently using TIP, with mean \pm standard deviation scores of $77.9 \pm 18.1$ on convenience, $69.0 \pm 15.9$ on effectiveness, $92.3 \pm 15.0$ on side effects, and $72.8 \pm 18.1$ on global satisfaction.

OLS regression indicated no significant differences in TSQM global satisfaction scores based on sex, age, lung function, nutritional status, CFQ-R respiratory symptom or treatment burden domain scores, or number of TIP cycles completed (Table 4). Following stepwise elimination, three variables were retained in the model: TSQM effectiveness, TSQM side effects, and respondent education level (model $R$-squared $=0.54$ ). Of these, only TSQM effectiveness was statistically significant, with higher satisfaction with effectiveness associated with higher global satisfaction.

\section{Discussion}

This study has shown that overall satisfaction with the use of TIP was high among patients with $\mathrm{CF}$ and $P$. aeruginosa infection. Preferences for TIP over a nebulized antibiotic were related to convenience factors, including shorter administration and cleaning time, portability, and ease of use. This is consistent with the findings of a real-world study of TIP in Ireland, as reported by Harrison et al, ${ }^{13}$ in which $94 \%$ of patients preferred TIP over nebulized tobramycin.

Clinician recommendation was the most important factor in choosing to start TIP therapy, although some patients also considered the anticipated benefits in relation to convenience, time to use, and ease of use. Patients found switching to TIP easy. The most common reason for stopping their last nebulized antibiotic was that it took too long to use and clinician recommendation. In contrast, for the subset of patients who had stopped TIP therapy, stopping was primarily related to the successful treatment of the infection or completion of treatment. Issues relating to side effects or difficulty using the devices were comparatively uncommon; these factors were reported as reasons for stopping TIP or a nebulized antibiotic by fewer than $20 \%$ of respondents.

Overall patient satisfaction with the use of TIP, as measured by the TSQM, was high. Global satisfaction for TIP use was related to greater satisfaction with perceived effectiveness but was not associated with sociodemographic characteristics, chronicity of use, or clinical status. The lack of association between treatment-experience and demographic and clinical characteristics confirms findings from an 
earlier study showing no relation between CFQ-R treatment burden scores and age, sex, and $\mathrm{FEV}_{1}{ }^{20}{ }^{20}$ At the same time, the present study found no relation between global satisfaction and treatment burden.

CF treatment is often complex and time consuming, resulting in considerable perceived treatment burden. ${ }^{21,22}$ While antipseudomonal antibiotic therapies have an important role in the treatment of infection in CF, nebulized formulations take considerable time to administer, as well as time needed to clean the device. ${ }^{14}$ Treatments that offer greater convenience have the potential to decrease treatment burden, which may in turn be associated with improved adherence to treatment. ${ }^{22}$ TIP has been shown to provide safe and effective treatment for $P$. aeruginosa infection in CF. ${ }^{11,12}$ One of these studies, a randomized, open-label study with 553 patients, also reported considerably shorter administration times for TIP than for tobramycin inhalation solution, with mean administration times of 5.6 minutes versus 19.7 minutes, respectively. The present real-world study confirms that this is an important feature of TIP from the patient perspective, with the greatest proportion of patients (48.6\%) rating time to administer as the most important feature of an inhaled antibiotic, followed by effectiveness (31.4\%). Moreover, $100 \%$ of patients expressed a preference for TIP over a nebulized antibiotic in relation to administration time, and between $94.3 \%$ and $97.1 \%$ of patients preferred TIP on other convenience-related factors.

\section{Limitations}

This study had a number of limitations. The small sample size and single-center design limit the generalizability of the results, although the findings are in accordance with those of other studies. Other patient factors such as geographic location, access to medication, and payer coverage were not explored in the context of this study and should be subject to future study. The noninterventional design allowed for the collection of real-world experience data but at the same time increased the potential for nonobserved factors to influence the results obtained. The data on treatment experiences and satisfaction emanated from patients currently taking TIP, either in combination with or having stopped taking a nebulized antibiotic. As has been observed previously, it is possible that current preferences for TIP are at least in part a reflection of an initial enthusiasm for a novel treatment. ${ }^{13}$ The study also required respondents to recall and attribute causality to past choices, for example, reasons for switching to or stopping TIP. It is possible that such retrospective reports are subject to post hoc rationalization, based on intervening treatment experiences.

\section{Conclusion}

This study builds on clinical studies of the safety and effectiveness of TIP by demonstrating patient preferences for TIP over nebulized antibiotics based on administration time, convenience, and ease of use. Global satisfaction for TIP use is not associated with patient characteristics, chronicity of use, or clinical status, but it is related to greater patient-perceived effectiveness. Further study is needed to show whether the high satisfaction and preferences for TIP are retained with prolonged use and to determine the long-term consequences of increased convenience on treatment burden, adherence, and health outcomes.

\section{Acknowledgment}

Data from this study was presented as an oral and poster presentation at the North American Cystic Fibrosis Conference in Atlanta, GA, USA; October 9-11, 2014.

\section{Disclosure}

JBP and WWC are employees of Novartis Pharmaceuticals. DW and PS are employees of RTI Health Solutions. RTI Health Solutions and Boston Children's Hospital each received funding from Novartis Pharmaceuticals for this study. The authors report no other conflicts of interest in this work.

\section{References}

1. Collaco J, McGready J, Green DM, et al. Effect of temperature on cystic fibrosis lung disease and infections: a replicated cohort study. PLoS One. 2011;6(11):e27784.

2. Edelstein MV, Skleenova EN, Shevchenko OV, et al. Spread of extensively resistant VIM-2-positive ST235 Pseudomonas aeruginosa in Belarus, Kazakhstan, and Russia: a longitudinal epidemiological and clinical study. Lancet Infect Dis. 2013;13(10):867-876.

3. Davies JC. Pseudomonas aeruginosa in cystic fibrosis: pathogenesis and persistence. Paediatr Respir Rev. 2002;3(2):128-134.

4. Mogayzel PJ Jr, Naureckas ET, Robinson KA, et al. Cystic fibrosis pulmonary guidelines. Am J Respir Crit Care Med. 2013;187(7): 680-689.

5. Döring G, Flume P, Heijerman H, Elborn JS; Consensus Study Group. Treatment of lung infection in patients with cystic fibrosis: current and future strategies. J Cyst Fibros. 2012;11(6):461-479.

6. Smyth AR, Bell SC, Bojcin S, et al. European Cystic Fibrosis Society Standards of Care: best practice guidelines. J Cyst Fibros. 2014; 13(Suppl 1):S23-S42.

7. Quittner AL, Buu A. Effects of tobramycin solution for inhalation on global ratings of quality of life in patients with cystic fibrosis and Pseudomonas aeruginosa infection. Pediatr Pulmonol. 2002;33(4): 269-276.

8. Ramsey BW, Pepe MS, Quan JM, et al. Intermittent administration of inhaled tobramycin in patients with cystic fibrosis. Cystic Fibrosis Inhaled Tobramycin Study Group. N Engl J Med. 1999;340(1): 23-30.

9. Murphy TD, Anbar RD, Lester LA, et al. Treatment with tobramycin solution for inhalation reduces hospitalizations in young CF subjects with mild lung disease. Pediatr Pulmonol. 2004;38(4):314-320. 
10. Sawicki GS, Signorovitch JE, Zhang J, et al. Reduced mortality in cystic fibrosis patients treated with tobramycin inhalation solution. Pediatr Pulmonol. 2012;47(1):44-52.

11. Konstan MW, Geller DE, Minić P, Brockhaus F, Zhang J, Angyalosi G. Tobramycin inhalation powder for $P$. aeruginosa infection in cystic fibrosis: the EVOLVE trial. Pediatr Pulmonol. 2011;46(3):230-238.

12. Konstan MW, Flume PA, Kappler M, et al. Safety, efficacy and convenience of tobramycin inhalation powder in cystic fibrosis patients: the EAGER trial. J Cyst Fibros. 2011;10(1):54-61.

13. Harrison MJ, McCarthy M, Fleming C, et al. Inhaled versus nebulised tobramycin: a real world comparison in adult cystic fibrosis (CF). JCyst Fibros. 2014;13(6):692-698.

14. Geller DE, Konstan MW, Smith J, Noonberg SB, Conrad C. Novel tobramycin inhalation powder in cystic fibrosis subjects: pharmacokinetics and safety. Pediatr Pulmonol. 2007;42(4):307-313.

15. Vandevanter DR, Geller DE. Tobramycin administered by the TOBI $\mathbb{R}$ Podhaler ${ }^{\circledR}$ for persons with cystic fibrosis: a review. Med Devices (Auckl). 2011;4:179-188.

16. Harris PA, Taylor R, Thielke R, Payne J, Gonzalez N, Conde JG. Research electronic data capture (REDCap) - a metadata-driven methodology and workflow process for providing translational research informatics support. J Biomed Inform. 2009;42(2):377-381.
17. Atkinson MJ, Sinha A, Hass SL, et al. Validation of a general measure of treatment satisfaction, the Treatment Satisfaction Questionnaire for Medication (TSQM), using a national panel study of chronic disease. Health Qual Life Outcomes. 2004;2:12.

18. Regnault A, Balp MM, Kulich K, Viala-Danten M. Validation of the treatment satisfaction questionnaire for medication in patients with cystic fibrosis. J Cyst Fibros. 2012;11(6):494-501.

19. Quittner A, Buu A, Messer MA, Modi AC, Watrous M. Development and validation of the cystic fibrosis questionnaire in the United States: a health-related quality-of-life measure for cystic fibrosis. Chest. 2005;128(4):2347-2354.

20. Sawicki GS, Sellers DE, Robinson WM. Associations between illness perceptions and health-related quality of life in adults with cystic fibrosis. Psychosom Res. 2011;70(2):161-167.

21. Ziaian T, Sawyer MG, Reynolds KE, et al. Treatment burden and health-related quality of life of children with diabetes, cystic fibrosis and asthma. J Paediatr Child Health. 2006;42(10):596-600.

22. Sawicki GS, Sellers DE, Robinson WM. High treatment burden in adults with cystic fibrosis: challenges to disease self-management J Cyst Fibros. 2009;8(2):91-96.
Patient Preference and Adherence

\section{Publish your work in this journal}

Patient Preference and Adherence is an international, peer-reviewed, open access journal that focuses on the growing importance of patient preference and adherence throughout the therapeutic continuum. Patient satisfaction, acceptability, quality of life, compliance, persistence and their role in developing new therapeutic modalities and compounds to optimize

\section{Dovepress}

clinical outcomes for existing disease states are major areas of interest for the journal. This journal has been accepted for indexing on PubMed Central. The manuscript management system is completely online and includes a very quick and fair peer-review system, which is all easy to use. Visit http://www. dovepress.com/testimonials.php to read real quotes from published authors. 